\title{
The Pattern of Osteoporosis in Chronic Obstructive Pulmonary Disease (COPD) in Bangladeshi Patients
}

\author{
Dr. Md. Monharul Islam Bhuiya ${ }^{1 *}$, Dr. Md. Jakaria Mahmud ${ }^{2}$, Dr. Must. Khalada Pervin Mita ${ }^{3}$
}

\author{
${ }^{1}$ Assistant Professor, Department of Medicine, Sylhet Womens Medical College, Sylhet, Bangladesh \\ ${ }^{2}$ Assistant Professor, Department of Respiratory Medicine, Sylhet M A G Osmani Medical College, Shylet, Bangladesh \\ ${ }^{3}$ Lecturer, Department of Anatomy, Sylhet M A G Osmani Medical College, Sylhet, Bangladesh
}

DOI: $10.36347 /$ sjams.2020.v08i05.031

| Received: 07.05.2020 | Accepted: 14.05.2020 | Published: 27.05.2020

*Corresponding author: Dr. Md. Monharul Islam Bhuiya

Objective: In this study our main goal is to assess the pattern of Osteoporosis in Chronic obstructive Pulmonary Disease (COPD) in Bangladeshi Patients. Method: This observational type study was carried out at the tertiary medical college and hospital from February 2017 to February 2018.A total of 50 patients of acute exacerbation meeting the selection criteria were consecutively included in the sample. Results: most of the patients belong to $>40$ years age group, $53.30 \%$ only $20 \%$ patients where female, where $80 \%$ were male out of 50 patients, $(56.7 \%)$ presented with current smoker and only (6.7\%) with nonsmoker person. According to T-score in lumbar spine, normal bone mineral density was in $(6.7 \%)$, osteopenia in $(28.3 \%)$ and osteoporosis in $(65.0 \%)$ patients. Conclusion: From our study we can conclude that, our findings highlight the potential value of studying BMD and reinforce the need for earlier identification and targeting of risk factors for osteoporosis as part of the management of COPD. However further study is required for better outcome.

Keywords: Osteoporosis, Chronic obstructive Pulmonary Disease (COPD), lumbar spine.

Copyright @ 2020: This is an open-access article distributed under the terms of the Creative Commons Attribution license which permits unrestricted use, distribution, and reproduction in any medium for non-commercial use (NonCommercial, or CC-BY-NC) provided the original author and source are credited.

\section{INTRODUCTION}

Chronic Obstructive Pulmonary Disease (COPD) is a major cause of morbidity and mortality in adults and is the fourth leading cause of death in the world [1]. It is characterized by chronic air flow limitation that is usually progressive [2]. COPD is now considered as a multicomponent disorder associated with systemic inflammation and extra pulmonary manifestations [3].

Osteoporosis is a systemic skeletal disease characterized by a low bone mineral density (BMD) and micro architectural changes in bones leading to an increased bone fragility and, in turn, resulting in an increased fracture risk. The prevalence of osteoporosis in COPD patients is 2-foldto 5-fold higher than in agematched subjects without air flow obstruction [4, 5]. Osteopenia is present in $35-72 \%$ of patients with COPD, and $36-60 \%$ of patients with COPD have been reported to be osteoporotic. Moreover, COPD patients have a 60 to $70 \%$ higher risk of death following hip fracture than people without COPD. It is therefore of high clinical importance to diagnose and treat osteoporosis in COPD according to international guidelines [6].
In this study our main goal is to evaluate the pattern of Osteoporosis in Chronic obstructive Pulmonary Disease (COPD) in Bangladeshi Patients.

\section{OBJECTIVE}

General Objective

- To assess the pattern of Osteoporosis in Chronic obstructive Pulmonary Disease (COPD) in Bangladeshi Patients.

Specific objective

- To detect basal characteristic of the patients

- To identify stages of COPD in the patients.

\section{Methodology}

Study type:

- The study was a observational study.

\section{Place and period of study}

- The study was carried out at the tertiary medical college and hospital from February 2017 to February 2018. 
Sample Size

- A total of 50 patients of acute exacerbation meeting the selection criteria were consecutively included in the sample.

\section{Inclusion Criteria}

- Previously diagnosed or newly diagnosed COPD according to GOLD criteria.

\section{Exclusion Criteria}

- Patients who had asthma, any disease affecting bones and calcium homeostasis or were receiving drugs related to bone metabolism

\section{Detailed Procedure}

In all cases a detailed history and clinical examination were done. Demographic data were collected including age, smoking history, inhaled corticosteroid use, alcohol consumption, menopausal history in case of female cases, comorbidities, duration of treatment, long term domiciliary oxygen therapy, body mass index, treatment history, hospital admission. Which were recorded in data entry from.

\section{Data Analysis}

- Collected data were analysed using software SPSS (Statistical Package for Social Sciences) version 11.5 for windows. Descriptive statistics were used to analyse the data. Analysed data were presented in the form of tables and charts with due interpretation.

\section{RESULT}

In Figure-1 shows age distribution of the patients where most of the patients belong to $>40$ years age group, $53.30 \%$. The following figure is given below in detail:

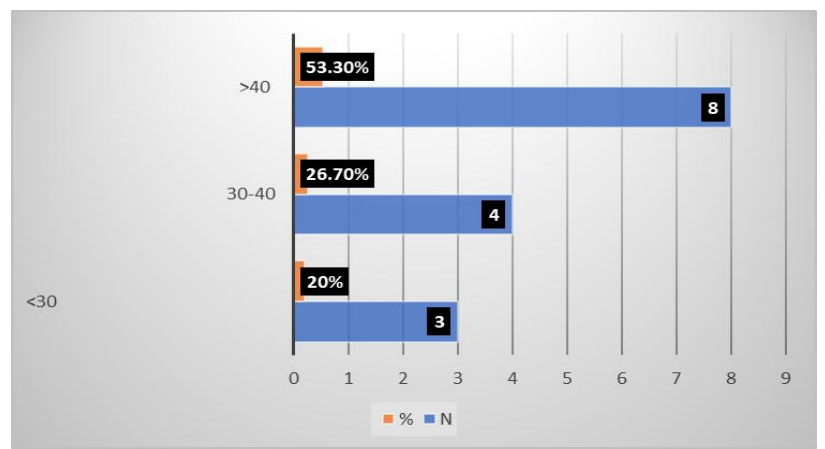

Fig-1: Age distribution of the patients

In Table-1 shows gender distribution of the patients where only $20 \%$ patients where female, where $80 \%$ were male. The following table is given below in detail:

Table-1: Gender distribution of the patients

\begin{tabular}{|l|l|}
\hline Gender & \% \\
\hline Male & $80 \%$ \\
\hline Female & $20 \%$ \\
\hline
\end{tabular}

In Figure-2 shows distribution of the patients according to occupation where most of the patients were day laborer, $63.60 \%$. The following figure is given below in detail:

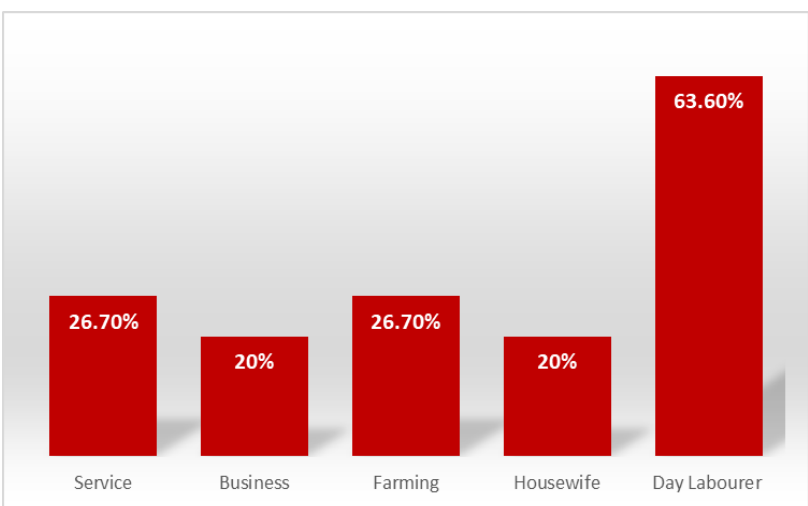

Fig-2: Distribution of the patients according to occupation

In Table- 2 shows baseline characteristics of the patients where out of 50 patients, $(56.7 \%)$ presented with current smoker and only $(6.7 \%)$ with nonsmoker person. The following table is given below in detail:

Table-2: Distribution of patients by baseline characteristics $(n=50)$

\begin{tabular}{|l|l|}
\hline Baseline characteristics & Percentage \\
\hline Weight $(\mathrm{kg})$, mean \pm SD & $54.92 \pm 9.17$ \\
\hline Height $(\mathrm{cm})$, mean \pm SD & $155.10 \pm 13.02$ \\
\hline BMI, mean \pm SD & $23.09 \pm 4.82$ \\
\hline Tobacco use: & \\
Current smoker & $56.7 \%$ \\
Ex-smoker & $36.7 \%$ \\
Never smoker & $6.7 \%$ \\
\hline
\end{tabular}

In Table-3 shows distribution of patients by severity of COPD where, majority ( $58 \%$ ) of the patients belong to stage III. The following table is given below in detail:

Table-3: Distribution of patients by Severity of COPD

\begin{tabular}{|l|l|}
\hline Severity of COPDPercentage \\
\hline Stage-II & 5 \\
\hline Stage-III & 58 \\
\hline Stage-IV & 39 \\
\hline
\end{tabular}

In Table-4 shows distribution of patients by BMI where according to $\mathrm{T}$-score in lumbar spine, normal bone mineral density was in $(6.7 \%)$, osteopenia in $(28.3 \%)$ and osteoporosis in $(65.0 \%)$ patients. the following table is given below in detail:

Table-4: Distribution of patients by BMI

\begin{tabular}{|l|l|}
\hline Activity level & $\begin{array}{l}\text { Femoral neck Percentage } \\
\text { Lumbar spine Percentage }\end{array}$ \\
\hline T-score & $-2.31 \pm 0.96-2.92 \pm 1.33$ \\
\hline Normal & $10.0 \% 6.7 \%$ \\
\hline Osteopenia & $40.0 \% 28.3 \%$ \\
\hline Osteoporosis & $50 \% 65.0 \%$ \\
\hline
\end{tabular}




\section{DISCUSSION}

In this study the age of the patients of COPD ranged from $<30$ to $>40$ years and most of the patients belong to $>40$ years age group, $53.30 \%$. This result was quite similar to the one study where mean age of the COPD patients was $62.8 \pm 5.6$ years. This result also correlated with other studies [6-8].

In this study we found that, 56.7\%) presented with current smoker and only (6.7\%) with nonsmoker person.

In one study it was reported that, mean smoking-pack year was36.8 \pm 17.2 (range, 10-90) packyears [8].

Another study said that, mean duration of COPD was $5.4 \pm 3.3$ years (range, $1-15$ years); the duration of COPD was1 to 5 years in $38(63.3 \%), 6$ to 10 years in $18(30.0 \%)$ and 11 to 15 years in $4(6.7 \%)$ patients [7]. One article reported that COPD duration was 1 year in $13.1 \%, 1-5$ years in $31.2 \%$ and above 5 years in $55.8 \%$ of patients [9].

In our study we noticed that, majority (58\%) of the patients belong to stage III. Which was supported by one study, where they found that GOLD stage-III was the most frequent severity of COPD constituted $56.7 \%$ cases, followed by stage-IV $(38.31 \%)$ and stage-II (5.0\%) [10].

One study showed that use of oral steroid in 7 (11.7\%) patients, inhaled steroid was in $38(63.3 \%)$ and 15(25.0\%) patients did not use any types of steroid [11]. Another study reported that oral corticosteroid in $4.5 \%$, inhaled corticosteroid in $54.1 \%$ and both oral and inhaled corticosteroid in $10.6 \%$ cases of COPD [12].

In our study, according to T-score in lumbar spine, normal bone mineral density was in $(6.7 \%)$, osteopenia in $(28.3 \%)$ and osteoporosis in $(65.0 \%)$ patients.

One study reported that, BMD in femoral neck was $0.77 \pm 0.17 \mathrm{gm} / \mathrm{cm} 2$ (range, 0.58 to 1.03 ) [8]. This result was almost similar to the other study where BMD in femoral neck was $0.74 \pm 0.11 \mathrm{gm} / \mathrm{cm} 2$ in men with chronic obstructive pulmonary disease [9].

\section{Conclusion}

From our study we can conclude that, our findings highlight the potential value of studying BMD and reinforce the need for earlier identification and targeting of risk factors for osteoporosis as part of the management of COPD. However further study is required for better outcome.

\section{REFERENCES}

1. Ramachandran K, Mani SK, Gopal GK, Rangasami S. Prevalence of Bone Mineral Density Abnormalities and Factors Affecting Bone Density in Patients with Chronic Obstructive Pulmonary Disease in a Tertiary Care Hospital in Southern India. JCDR. 2016; 10(9): OC32-4.

2. Barnes PJ. Chronic obstructive pulmonary disease. N Engl J Med. 2000; 343(4): 269-78.

3. Rabe KF, Hurd S, Anzueto A, Barnes PJ, Buist SA, Calverley P, Fukuchi Y, Jenkins C, Rodriguez-Roisin R, Van Weel C, Zielinski J. Global strategy for the diagnosis, management, and prevention of chronic obstructive pulmonary disease: GOLD executive summary. American journal of respiratory and critical care medicine. 2007 Sep 15;176(6):532-55.

4. Stone AC, Nici L. Other systemic manifestations ofchronic obstructive pulmonary disease. Clin Chest Med. 2007; 28(3): 553-5.

5. Graat-Verboom 1, Wouters EFM, Smeen FWJM, Vanden Borne BEEM, Lunde R, Spruit MA. Current status ofresearch on osteoporosis in COPD: a systematic review. Eur Respir J. 2009; 34(1): 209-18.

6. Sabit R, Bolton CE, Edwards PH, Pettit RJ, Evans WD, McEniery CM, Wilkinson IB, Cockcroft JR, Shale DJ. Arterial stiffness and osteoporosis in chronic obstructive pulmonary disease. American journal of respiratory and critical care medicine. 2007 Jun 15;175(12):1259-65.

7. Bolton CE, Ionescu AA, Shiels KM, Pettit RJ, Edwards PH, Stone MD, Nixon LS, Evans WD, Griffiths TL, Shale DJ. Associated loss of fat-free mass and bone mineral density in chronic obstructive pulmonary disease. American journal of respiratory and critical care medicine. 2004 Dec 15;170(12):1286-93.

8. Incalzi RA, Caradonna P, Ranieri P, Basso S, Fuso L, Pagano F, Ciappi G, Pistelli R. Correlates of osteoporosis in chronic obstructive pulmonary disease. Respiratory medicine. 2000 Nov 1;94(11):1079-84.

9. Iqbal F, Michaelson J, Thaler L, Rubin J, Roman J, Nanes MS. Declining bone mass in men with chronic pulmonary disease: contribution of glucocorticoid treatment, body mass index, and gonadal function. Chest. 1999; 116(6): 1616-24.

10. De Luise C, Brimacombe M, Pedersen L, Sorensen HT. Chronic obstructive pulmonary disease and mortality following hip fracture: a population-based cohort study. Eur J Epidemiol. 2008; 23(2): 115-22.

11. World Health organization (WHO). Prevention and management of osteoporosis: report of a WHO scientific group. http://whqlibdoc. who.int/trs/WHO TRS 921. pdf. Accessed on May 10, 2015.

12. Leslie WD, Tsang JF, Caetano PA, Lix LM. Number of osteoporotic sites and fracture risk assessment: a cohort study from the Manitoba Bone Density Program. J Bone Min Res. 2007; 22(3): 476-83. 